\title{
Antiangiogenic Effect of Ficus deltoidea Jack Standardised Leaf Extracts
}

\author{
Armaghan Shafaei ${ }^{1}$, Nahdzatul Syima Muslim ${ }^{2}$, Zeyad D Nassar ${ }^{2,3}$, Abdalrahim \\ FA Aisha ${ }^{1,2}$, Amin Malik Shah Abdul Majid ${ }^{2}$ and Zhari Ismail ${ }^{1^{*}}$ \\ ${ }^{1}$ Department of Pharmaceutical Chemistry, ${ }^{2}$ EMAN Testing \& Research Laboratory, Department of Pharmacology, School of \\ Pharmaceutical Sciences, Universiti Sains Malaysia, Minden 11800, Pulau Pinang, Malaysia, ${ }^{3}$ School of Pharmacy, University \\ of Queensland, Brisbane, QLD, Australia
}

*For correspondence: Email: ismailzhari@gmail.com; Tel: +604-653-2242

Received: 4 June 2013

Revised accepted: 16 March 2014

\begin{abstract}
Purpose: To standardise the methanol and aqueous extracts of Ficus deltoidea leaf by developing a reverse phase high performance liquid chromatography (RP-HPLC) for determination of the ursolic acid content and to investigate their antiangiogenic activity.

Methods: To prepare the water extract (FD-A), the powder of the plant was extracted with water under reflux for $24 \mathrm{~h}$ at $50{ }^{\circ} \mathrm{C}$. The methanol extract (FD-M) was prepared using Soxhlet extractor for $24 \mathrm{~h}$ at $50{ }^{\circ} \mathrm{C}$. The extracts were standardised for ursolic acid content by reverse phase high performance liquid chromatography (RP-HPLC), as well as by total phenolic and flavonoid contents. Antiangiogenic activity was studied using ex vivo rat aortic rings and in vivo chick chorioallantoic membrane angiogenesis models. The anti-proliferative effect of the extracts against normal human endothelial cells and two cancer cell lines was assessed by 3-(4,5-dimethylthiazol-2-yl)-2,5-diphenyl tetrazolium bromide (MTT) assay.

Results: In rat aortic rings, methanol and water extracts inhibited the outgrowth of microvessels with IC50 values of $48.2 \pm 1.1$ and $62.7 \pm 1.4 \mu \mathrm{g} \mathrm{mr}^{1}$, respectively. Methanol and water extracts at doses of $100 \mu \mathrm{g} \mathrm{disc}^{-1}$ also inhibited vascularisation of chick embryo chorioallantoic membrane with inhibition values of of $62.0 \pm 6.3$ and $43.3 \pm 4.8 \%$, respectively. In addition, both extracts showed potent cytotoxicity against breast and colon cancer cells while demonstrating non-cytotoxic activity against normal endothelial cells. Furthermore, the two extracts showed relatively high concentration of ursolic acid, total phenolics and flavonoids associated with potent antiangiogenic activity.

Conclusion: The inhibition of angiogenesis by $F$. deltoidea extracts may be attributed to the relatively high ursolic acid content as well as the presence of antioxidant compounds of phenolics and flavonoids in the extracts.
\end{abstract}

Keywords: Ficus deltoidea, Antiangiogenesis, Ursolic acid, Cytotoxicity, Antioxidant

Tropical Journal of Pharmaceutical Research is indexed by Science Citation Index (SciSearch), Scopus, International Pharmaceutical Abstract, Chemical Abstracts, Embase, Index Copernicus, EBSCO, African Index Medicus, JournalSeek, Journal Citation Reports/Science Edition, Directory of Open Access Journals (DOAJ), African Journal Online, Bioline International, Open-J-Gate and Pharmacy Abstracts

\section{INTRODUCTION}

Medicinal plants have been used for centuries in folk medicine in the treatment of various diseases and today, they still play an important role in health. Ficus deltoidea (FD) Jack (Moraceae) is a traditional medicinal plant widely distributed in Southeast Asia. In Malaysia, FD is known as "mas cotek" [1,2]. Traditionally, the plant has been utilised in treating gout, high blood pressure, pneumonia, diarrhoea, skin infections, diabetes and to improve blood circulation [3]. Previous studies have shown that FD leaves possess antinociceptive, wound 
healing and antioxidant properties [1,3,4]. Previous research on FD showed the presence of relatively high content of polyphenols, flavonoids, which are known as antioxidant compounds, amino acids, vitamins, carbohydrates, and purine alkaloids. Presence of a number of antioxidant compounds is known to possess various pharmacological activities including antiangiogenic and cytotoxic effects on a number of human cancer cell lines [1-3].

Angiogenesis, the formation of new blood vessels, plays a critical role in pathogenesis of various human diseases such as cancer, psoriasis, arterial plaque formation, ocular neovascularization, gastrointestinal ulcers, rheumatoid arthritis, and diabetic retinopathy [5]. Therefore, inhibition of angiogenesis may provide promising therapies for several human life threatening ailments.

Standardisation of herbal extracts and preparations provides an important tool to study the chemical profile and to evaluate reproducibility of extraction procedures, pharmacological effects, and provides the markers for stability and pharmacokinetics studies.

In this context, this study sought to standardise FD leaf extracts and to investigate their antiangiogenic activity due to their high content of phytochemical components as well as local use of FD leaf for curing diseases.

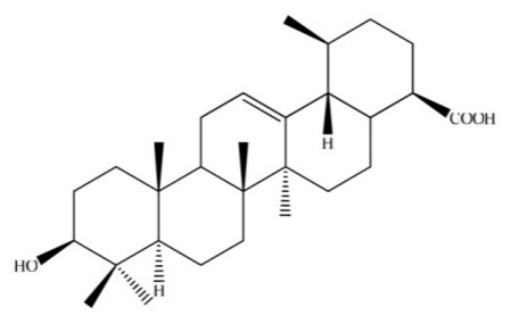

Figure 1: Structure of ursolic acid.

\section{EXPERIMENT}

\section{Chemicals and reagents}

Earles' salt M199 medium, trypsin, Dulbecco's modified eagle medium (DMEM), minimum essential medium (MEM), fibrinogen and foetal bovine serum (FBS) were obtained from BioDiagnostics (Petaling Jaya, Selangor, Malaysia). Aprotinin, L-glutamine, thrombin, sodium chloride, amphotericin B, gentamycin, 6aminocaproic acid, suramin, dimethylsulfoxide (DMSO), phosphate buffered saline (PBS), 3(4,5-dimethylthiazol-2-yl-2,5-diphenyl)tetrazolium bromide (MTT), agarose, ursolic acid, quercetin, gallic acid, Folin-Ciocalteau reagent, sodium carbonate, aluminium chloride and potassium acetate were purchased from Sigma-Aldrich (Subang Jaya, Selangor, Malaysia). Human umbilical vein endothelial cells (HUVECs), human hormone resistant breast cancer cells (MDA-MB-231) and human colorectal carcinoma cells (HCT 116) were purchased from ATCC (Manassas, Virginia). Endothelial cell medium (ECM) was obtained from Team Medical Scientific (Shah Alam, Selangor, Malaysia). HPLC-grade of acetonitrile and orthophosphoric acid were purchased from Merck (Petaling Jaya, Selangor, Malaysia). Deionised water for HPLC was prepared using Ultra pure water purifier system (Elgastat, Bucks, UK).

\section{Plant material and extraction}

The leaves of the plant (Ficus deltoidea) were purchased from Herbagus Sdn. Bhd. PenangMalaysia and identified by Mr. Shunmugam of the School of Biological Sciences, University Sains Malaysia. A voucher specimen (no. 11204) was deposited at the herbarium of School of Biological Sciences, University Sains Malaysia. The batch of leaves for the current study was collected at the end of July and early in August, 2010 , oven-dried at $40^{\circ} \mathrm{C}$ and then pulverised into fine powder using a milling machine (Retsch $\mathrm{GmbH}$, Germany). To prepare the water extract (FD-A), $100 \mathrm{~g}$ powder was extracted with 1000 $\mathrm{mL}$ water under reflux for $24 \mathrm{~h}$ at $50{ }^{\circ} \mathrm{C}$. The methanol extract (FD-M) was prepared using Soxhlet extractor for $24 \mathrm{~h}$ at $50{ }^{\circ} \mathrm{C}$ at the same solvent to plant powder ratio. After cooling, the extracts were filtered using Whatman filter paper no. 1 , concentrated at $50^{\circ} \mathrm{C}$ under vacuum using a rotary evaporator (RE121 Buchi, Switzerland), and dried using a freeze-dryer (Labconco, USA).

\section{Determination of ursolic acid content by RP- HPLC}

Agilent 1100 HPLC system equipped with a degasser, a quaternary pump, auto sampler, a column oven and UV detector was used. Separation was performed on Zorbax Eclipse $C_{18}$ SB-Aq column $(250 \times 4.6 \mathrm{~mm} \times 5 \mu \mathrm{m})$ fitted with analytical guard column $(4.6 \times 12.5 \mathrm{~mm}, 5 \mu \mathrm{m})$ (Agilent Technologies, USA). Elution was performed with an isocratic mobile phase comprising of acetonitrile (65\%) and $1.25 \%$ $\mathrm{H}_{3} \mathrm{PO}_{4}(35 \%)$, flow rate was $1.2 \mathrm{~mL} \mathrm{~min}{ }^{-1}$, injection volume was $20 \mu \mathrm{L}$, column temperature was $25^{\circ} \mathrm{C}$, detection was carried out at $210 \mathrm{~nm}$ and data acquisition was performed by Chemstation A.08.03.

The method was validated for linearity, accuracy, precision, limits of detection (LOD), and 
quantification (LOQ) according to a previously described method [6]. Linearity was determined as the regression coefficient $\left(R^{2}\right)$ of calibration curve constructed at 8 concentrations. Accuracy was evaluated as the percentage recovery of reference compound added to extracts. Precision of peak area was determined as a relative standard deviation (\%RSD) of intraday and interday data $(n=6)$. LOD and LOQ were established at signal to noise ratio $(\mathrm{S} / \mathrm{N})$ of 3 and 10 , respectively. The ursolic acid content in FD extracts was calculated by using the calibration equation of reference compound.

\section{Determination of total phenolics}

Total phenolic content was determined as described previously [7]. Briefly, $20 \mu \mathrm{ll}$ extract $\left(4 \mathrm{mg} \mathrm{m}^{-1}\right)$ or gallic acid $(0.0625-4$ $\mathrm{mg} \mathrm{ml}^{-1}$ ) was added to $1.58 \mathrm{ml}$ deionised water and $100 \mu \mathrm{l}$ folin-ciocalteu reagent, mixed thoroughly and incubated at room temperature (rt) for $8 \mathrm{~min}$. Subsequently, $300 \mu \mathrm{l}$ of $20 \% \mathrm{na}_{2} \mathrm{CO}_{3}$ was added, incubated for $2 \mathrm{~h}$, and absorbance was measured at $765 \mathrm{~nm}$. The results are expressed as average $\mathrm{mg}$ gallic acid equivalents per gram of the extract $(n=3)$.

\section{Determination of total flavonoids}

Total flavonoid content determined using a previously described method [8]. Aluminium chloride $(0.1 \mathrm{~mL}, 10 \% \mathrm{w} / \mathrm{v}), 0.1 \mathrm{~mL}$ of $1 \mathrm{M}$ potassium acetate solution, $1.5 \mathrm{~mL}$ methanol, and $2.8 \mathrm{~mL}$ of distilled deionised water were added to $500 \mu \mathrm{L}$ of extract $(4 \mathrm{mg}$ $\left.\mathrm{mL}^{-1}\right)$ or quercetin $\left(0.0078-4 \mathrm{mg} \mathrm{mL}^{-1}\right)$, mixed, and incubated at room temperature (RT) for $30 \mathrm{~min}$. Absorbance was measured at $415 \mathrm{~nm}$. Aluminium chloride was substituted by water for the blank. Total flavonoid content was determined, as $\mathrm{mg}$ quercetin equivalents per gram of the extract $(n=3)$, by applying quercetin calibration equation.

\section{Experimental animals}

The 8 to 12 weeks old Sprague Dawley male rats were obtained from the Animal House Unit, Universiti Sains Malaysia. The animals were kept for two weeks in transient animal house before carrying out the experiment. Moreover, well ventilated cages with $12 \mathrm{~h}$ of light as well as food and water were provided for the animals. The animals were sacrificed by suffocated under carbon dioxide $\left(\mathrm{CO}_{2}\right)$.

\section{Rat aortic ring assay}

The assay was performed following previously described protocols [9]. In brief, $1-\mathrm{mm}$ thick rings of thoracic aortas were seeded in fibrin clots, treated at various concentrations of the extracts $(5-100 \mu \mathrm{g}$ $\mathrm{mL}^{-1}$ ) and incubated at $37{ }^{\circ} \mathrm{C}$ in a humidified $\mathrm{CO}_{2}$ incubator for 5 days. The second layer medium was replaced with a fresh one on day 4 , and the outgrowth of blood vessels in the explants was quantified on day 5 using an inverted light microscope supplied with Leica QWin imaging software [10]. Suramin $(100 \mu \mathrm{g} / \mathrm{ml})$ and $1.0 \%$ dimethyl sulfoxide (DMSO) were used as positive and negative controls respectively.

\section{Cell viability assay}

The effect of the extracts on cell viability was evaluated by MTT assay. The cells were treated with extract or $1.0 \%$ DMSO for $48 \mathrm{~h}$, following a previously described method [11]. The absorbance was taken at $570 \mathrm{~nm}$ using a microtitre plate reader (Tecan, Switzerland), and the results are presented as \% cell viability relative to negative control.

\section{In vivo chorioallantoic membrane (CAM) assay}

The antiangiogenic effect of the extracts was screened in vivo using a modified fertilised chicken embryos assay [12]. Briefly, 5-day old fertilised eggs were obtained from a local hatchery and $5 \mathrm{~mL}$ albumin was withdrawn. The samples were prepared as discs in $1.2 \%$ of agarose at $100 \mu \mathrm{g} \mathrm{disc}{ }^{-1}$. Discs containing the vehicle (ethanol $1 \%$ ) were used as negative control. Treatments were applied on CAMs through a small window opened in the shell, and incubated for $24 \mathrm{~h}$. CAMs were then photographed under a dissecting microscope ( $\mathrm{n}$ $=6)$, and blood vessels counted. The results are expressed as mean inhibition \pm SD $(\%, n=6)$.

\section{Ethical approval}

All the procedures were carried out according to the Animal Ethics Guidelines of Universiti Sains Malaysia which is based on standard protocols for the use of laboratory animals [13] and with approval reference no. USM/Animal Ethics Approval/2011/(66)(302).

\section{Statistical analysis}

The results are presented as mean \pm SD. Differences between groups were compared by 
one-way ANOVA and differences were considered significant at $p<0.05$. Statistical analysis was carried out using SPSS version 16.0 (SPSS, Chicago, Illinois).

\section{RESULTS}

\section{Phytochemical profile}

HPLC chromatograms of ursolic acid are shown in Figure 2. The peak corresponding to ursolic acid in the extracts was assigned by comparing its retention time with that of ursolic acid reference compound. Good linearity $\left(R^{2}=0.9999\right)$ was obtained in the concentration range $\left(0.1-1000 \mu \mathrm{g} \mathrm{mL}{ }^{-1}\right)$. The linear regression equation was $y=$ 7.2265x - 14.754. LOD and LOQ were 1.0 and $5.0 \mu \mathrm{g} \mathrm{mL} \mathrm{m}^{-1}$, respectively. Precision, as $\%$ RSD of the peak area, was $<3 \%$ (Table $1)$. Accuracy, as $\%$ recovery of ursolic acid, was in the range 98.3 - $102.5 \%$ with \%RSD $<3 \%$, which indicates good reproducibility of the method (Table 2). Ursolic acid content of FD extracts, as $\mathrm{mg} \mathrm{g}^{-1}$ extract, was $4.3 \pm 0.2$ and $2.5 \pm 0.03$ for methanol (FD-M) and aqueous (FD-A) extracts, respectively.
Table 1: Intra-day and inter-day precision of ursolic acid (based on HPLC method, $n=6$ ).

\begin{tabular}{|c|c|c|c|c|}
\hline \multirow[t]{2}{*}{$\begin{array}{l}\text { Concentration } \\
\left(\mu \mathrm{g} \mathrm{mL}^{-1}\right)\end{array}$} & \multicolumn{2}{|c|}{$\begin{array}{l}\text { Intra-day } \\
(n=6)\end{array}$} & \multicolumn{2}{|c|}{$\begin{array}{l}\text { Inter-day } \\
(n=6)\end{array}$} \\
\hline & $\begin{array}{l}\text { Mean } \\
(\%)\end{array}$ & $\begin{array}{l}\text { RSD } \\
(\%)\end{array}$ & $\begin{array}{l}\text { Mean } \\
(\%)\end{array}$ & $\begin{array}{l}\text { RSD } \\
(\%)\end{array}$ \\
\hline 50 & 92.9 & 3.0 & 94.8 & 2.9 \\
\hline 100 & 107.2 & 0.1 & 101.9 & 2.0 \\
\hline 200 & 101.6 & 0.2 & 103.1 & 3.0 \\
\hline
\end{tabular}

The results are shown as \% recovery of ursolic acid added to methanol (FD-M) and water (FD-A) extracts of $F$. deltoidea.

Table 2: Accuracy of the HPLC method

\begin{tabular}{lllll}
\hline $\begin{array}{l}\text { Concentration } \\
\left(\boldsymbol{\mu g} \mathbf{~ m L}^{-1}\right)\end{array}$ & \begin{tabular}{l} 
FD-M \\
\cline { 2 - 5 }
\end{tabular} & $\begin{array}{l}\text { Recovery RSD } \\
(\mathbf{( \% )}\end{array}$ & $\begin{array}{l}\text { Recovery } \\
\mathbf{( \% )}\end{array}$ & $\begin{array}{l}\text { RSD } \\
(\%)\end{array}$ \\
\hline 55 & 98.3 & 1.2 & 100.1 & 1.8 \\
100 & 102.5 & 0.7 & 101.9 & 3.0 \\
180 & 100.5 & 0.3 & 99.5 & 1.5 \\
\hline
\end{tabular}

The total phenolic and flavonoid contents of FD$M$ extract was $118.1 \pm 2.6$ and $469.6 \pm 5.6 \mathrm{mg} \mathrm{g}^{-}$ 1 , while for FD-A extract the values were $12.6 \pm$ 1.0 and $16.8 \pm 0.3 \mathrm{mg} \mathrm{g}^{-1}$, respectively.

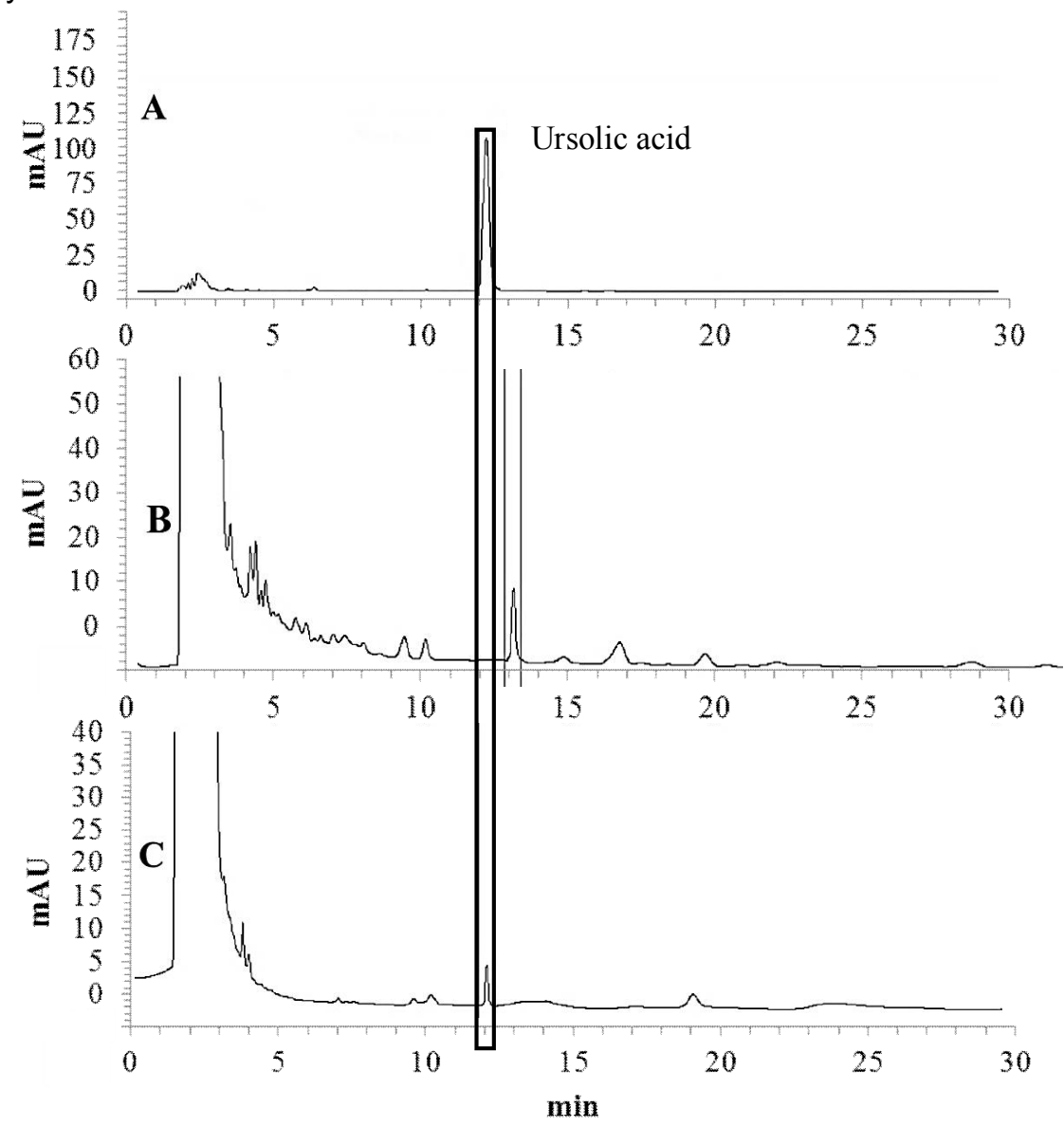

Figure 2: HPLC chromatograms of $F$. deltoidea extracts and ursolic acid. Note: Ursolic acid (A) standard, FD-M extract (B), and FD-A extract (C). 


\section{Antiangiogenic effect of extracts}

The antiangiogenic effect of the extracts was confirmed by rat aortic ring assay data. Figure 3 shows normal microvessels outgrowth from the untreated aortic rings. On the other hand, aortic rings treated with FD-M and FD-A extracts exhibited outgrowth reduction with $\mathrm{IC}_{50}$ of $48.2 \pm 1.1$
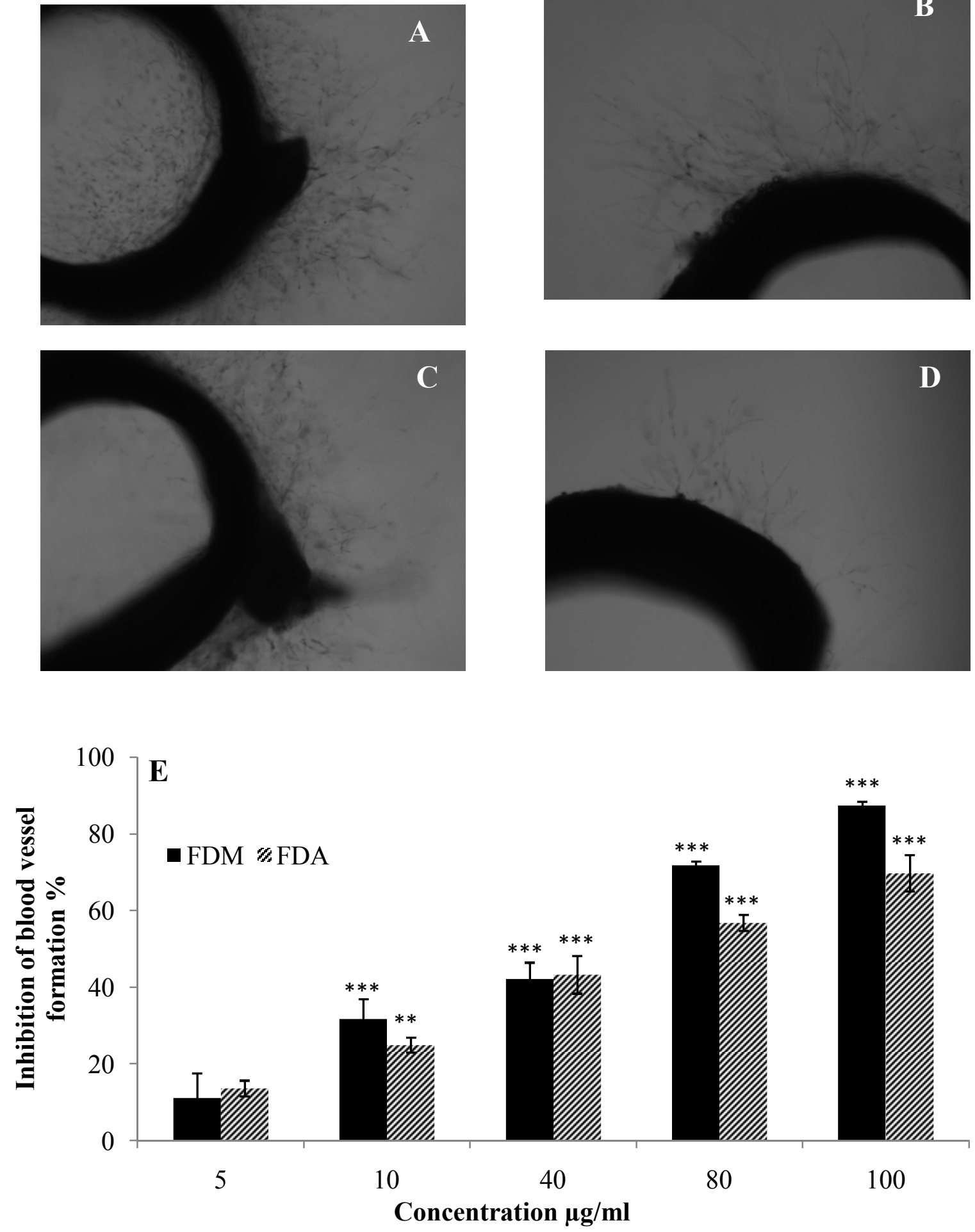

Figure 3: Effect of $F$. deltoidea leaf extracts on microvessels outgrowth in rat aortic rings. Note: $1 \%$ DMSO (A), FD-M extract (B), FD-A extract (C), Suramin $100 \mathrm{~g} \mathrm{~mL}^{-1}(\mathrm{D})$, and dose dependent relationship of FD extracts on the microvessels outgrowth $(E)$. Data are presented as mean $\pm S D(n=3) ;{ }^{* *} p<0.05$ and ${ }^{* * *} p<0.001$ and $62.7 \pm 1.4 \mu \mathrm{g} \mathrm{mL} \mathrm{mL}^{-1}$, respectively. Both extracts showed significant dose-dependent inhibition $(p<0.05$ and $p<0.001)$ compared with untreated aortic rings. Suramin (standard, $100 \mu \mathrm{g} \mathrm{mL} \mathrm{m}^{-1}$ ) showed $100 \%$ inhibition of microvessels outgrowth.
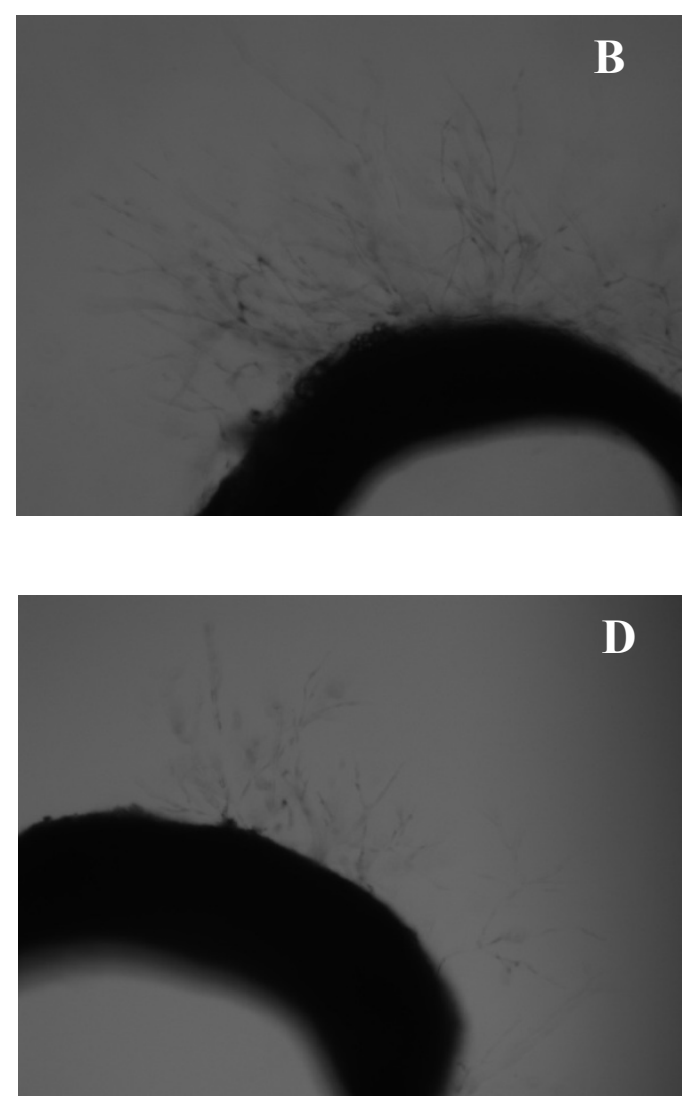

D

Trop J Pharm Res, May 2014; 13(5): 765 


\section{Effect on cell viability}

The anti-proliferative effects of the extracts on HUVECs, HCT 116 and MDA-MB-231 cells are shown in Fig 4. The extracts showed a dose dependent anti-proliferative activity after $48 \mathrm{~h}$ of treatment compared to negative control in this study. $I C_{50 s}$ was deduced from the logarithm regression equations obtained by plotting $\%$ cell viability versus concentration. The extracts were non-cytotoxic against HUVECs, but showed potent cytotoxic effect on the hormone-resistant breast cancer (MDA-MB-231) and colon cancer (HCT 116) cells (Table 3).

Table 3: Median inhibitory concentrations $\left(\mathrm{IC}_{50}\right)$ of $F$. deltoidea extracts on human cancer and normal cell lines. Results are shown as mean \pm SD $(n=3)$.

\begin{tabular}{lccc}
\hline \multirow{2}{*}{ Extract } & \multicolumn{3}{c}{$\mathrm{IC}_{50}\left(\boldsymbol{\mu g ~ \mathrm { L } ^ { - 1 } )}\right.$} \\
\cline { 2 - 4 } & HUVECs & MDA-MB- & HCT 116 \\
\hline FD-M & $377.2 \pm 5.6$ & $22.2 \pm 1.2$ & $36.6 \pm 2.2$ \\
\hline FD-A & $387.5 \pm 10.0$ & $22.6 \pm 0.6$ & $35.5 \pm 0.7$ \\
\hline
\end{tabular}

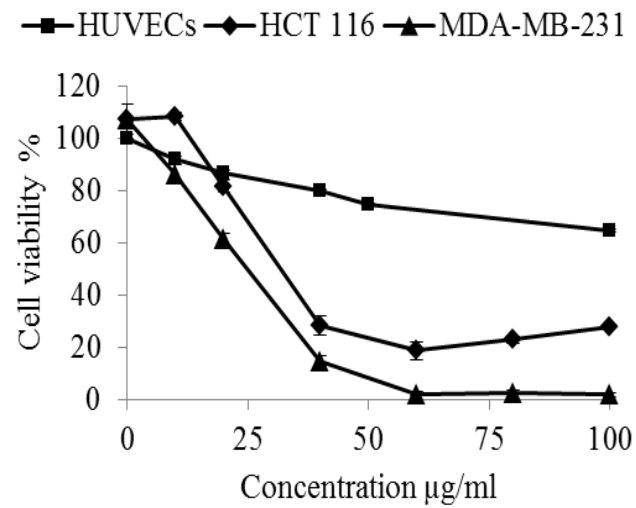

A

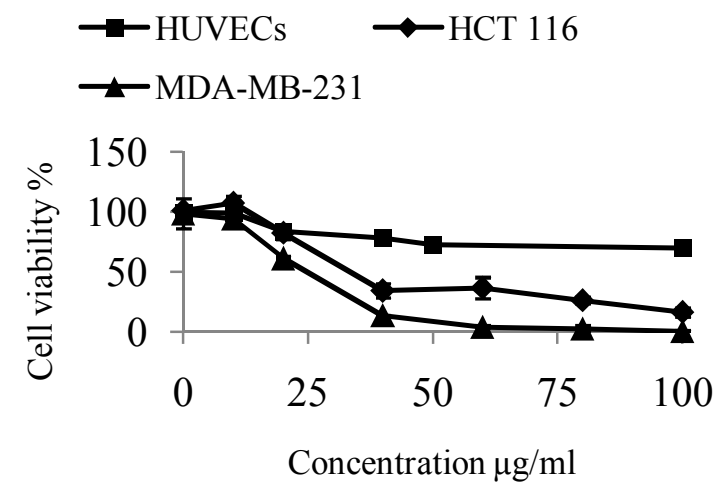

B

Figure 4: Anti-proliferative effect of (A) FD-A and (B) FD-M extracts against HUVECs, HCT 116 and MDA-MB-231 cell lines. Values are shown as mean $\pm \operatorname{SD}(n=3)$.

\section{In vivo antiangiogenic effect of the extracts on neovascularisation}

Vascularisation in the fertilised chick embryos was significantly inhibited at $100 \mu$ disc $^{-1}$ of FD$\mathrm{M}$ and FD-A extracts. Figure 5 shows normal vasculature pattern obtained in untreated CAMs with primary, secondary and tertiary vessels and with dendritic branching pattern, whereas the CAMs treated with the extracts showed inhibition of new blood vessels growth as well as distortion in the existing vasculature architecture. Inhibition was $62.0 \pm 6.3$ (FD-M) and $43.3 \pm 4.8 \%$ (FD-A).

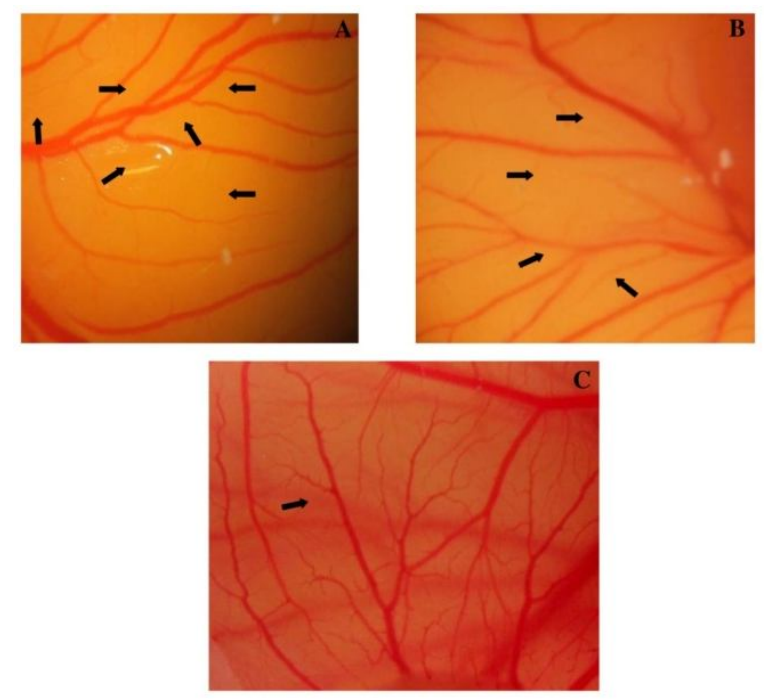

Figure 5: Effect of $F$. deltoidea extracts on neovascularisation in chick chorioallantoic membrane. CAM treated with FD-M extract at $100 \mu \mathrm{g} \operatorname{disc}^{-1}(\mathrm{~A})$, FD-A extract at $100 \mu \mathrm{g} \operatorname{disc}^{-1}(B)$, and $1 \%$ ethanol (C).

\section{DISCUSSION}

Phytochemical analysis of FD extracts reveals the presence of relatively high content of ursolic acid, total phenolics and flavonoids with the highest concentration obtained in FD-M extract. Ursolic acid is a triperpene distributed widely in the plant kingdom. The compound is gaining more and more interest due to its wide range of pharmacological properties such as liver protection [14], anti-inflammatory [15], antiangiogenic [16], chemopreventive [17], anticancer, and antioxidant effects [18]. The RPHPLC method for quantification of ursolic acid in FD reported is rapid, reproducible, and precise.

FD extracts potently inhibited the outgrowth of microvessels in rat aortic rings in a dosedependent manner. In order to test if the antiangiogenic activity observed is due to direct cytotoxic effect on endothelial cells or due to inhibition of other angiogenesis cascade mechanisms, the cytotoxicity of FD extracts was 
tested against HUVECs and two cancer cell lines (HCT 116 and MDA-MB-231). Cell viability results show that FD extracts are not cytotoxic to HUVECs; according to the National Cancer Institute $(\mathrm{NCl})$ extracts with $\mathrm{IC}_{50}>20 \mu \mathrm{g} \mathrm{mL} \mathrm{m}^{-1}$ are not considered cytotoxic [19]. However, the extracts showed higher cytotoxicity towards the colon cancer (HCT 116) and breast cancer (MDA-MB-231) cells. In order to illustrate the antiangiogenic potential of FD in vivo, the extracts were tested on chick CAMs as an in vivo angiogenesis model [20]. The results showed that FD extracts significantly inhibited the new blood vessels formation and distorted the existing vasculature. This result further supports the antiangiogenic activity observed in vitro.

Angiogenesis plays an important role in pathogenesis of various human diseases such as cancer, psoriasis, and diabetic retinopathy [5]. Therefore, $F$. deltoidea extracts, as a natural angiogenesis inhibitor, may provide new candidates for the treatment of these diseases.

Previous studies showed that ursolic acid may inhibit the different steps of the angiogenesis process using bovine aortic endothelial cells, notably down regulation of VEGF expression level. In support of the our findings, extensive studies have shown antiangiogenic effect of ursolic acid, phenolics and flavonoids compounds [16]. Therefore, the antiangiogenic activity of FD extracts may likely be due to the presence of ursolic acid, phenolics and flavonoids.

The selective and potent anti-proliferative effect obtained against the cancerous cells, but not on normal cells, highlights FD as a potential source of new anti-cancer candidates.

\section{CONCLUSION}

Taken together, the inhibition of angiogenesis observed in rat aortic ring and CAM assays is not due to direct cytotoxicity on endothelial cells, but to inhibition of other vital steps in angiogenesis cascade which needs further investigation. The antiangiogenic effect of FD extract may be related to the presence of relatively high contents of ursolic acid, phenolics and flavonoids. The selective cytotoxicity towards colon and breast cancer cell lines, and anti-angiogenic effect indicates the potential anti-cancer effect of FD extracts.

\section{ACKNOWLEDGEMENT}

The author would like to acknowledge Universiti Sains Malaysia for providing a grant (no. 1001/PFARMASI/833016) to carry out this work.

\section{REFERENCES}

1. Sulaiman MR, Hussain MK, Zakaria ZA, Somchit MN, Moin S, Mohamad AS, Israf DA. Evaluation of the antinociceptive activity of Ficus deltoidea aqueous extract. Fitoterapia 2008; 79: 557-561.

2. Zunoliza A, Hussain K, Zhari I, Rasadah MA, Mazura P, Jamaludin $F$, Sahdan R. Evaluation of extracts of leaf of three Ficus deltoidea varieties for antioxidant activities and secondary metabolites. Pharmacognosy Res 2009; 4 216-223.

3. Hakiman M, Mazziah M. Non enzymatic and enzymatic antioxidant activities in aqueous extract of different Ficus deltoidea accessions. J Med Plant Res 2009; 3 120-131.

4. Abdulla MA, K.A.Ahmed, Abu-Luhoom FM, Muhanid M. Role of Ficus deltoidea extract in the enhancement of wound healing in experimental rats. Biomedical Research 2010; 21: 241-245.

5. Wang S, Zheng Z, Weng Y, Yu Y, Zhang D, Fan W, Dai $R$, $H u$ Z. Angiogenesis and anti-angiogenesis activity of Chinese medicinal herbal extracts. Life Sci 2004; 74(20): 2467-2478.

6. Siddiqui MJA, Zhari I. Simultaneous analysis of bioactive markers from Orthosiphon stamineus Benth leaves extracts by reverse phase high performance liquid chromatography. Trop J Pharm Res 2011; 10: 97-103.

7. Schalbert A, Williamson G. Dietary intake and bioavailability of polyphenols. American Society for Nutrition Food and Chemistry 1989; 37: 1324-1329.

8. Woisky RG, Salatino A. Analysis of propolis: some parameters and procedures for chemical quality control. Journal of Agricultural Research 1998; 37: 99-105.

9. Aisha AFA, Abu-Salah KM, Darwis Y, Abdul Majid AMS. Screening of Antiangiogenic Activity of Some Tropical Plants by Rat Aorta Ring Assay. Int J Pharamcol 2009; 5(6): 370-376.

10. Nicosia RF, Lin YJ, Hazelton D, Qian X. Endogenous regulation of angiogenesis in the rat aorta model. Role of vascular endothelial growth factor. Am J Pathol 1997; 151(5): 1379-86.

11. Mosmann T. Rapid colorimetric assay for cellular growth and survival: application to proliferation and cytotoxicity assays. J Immunol Methods 1983; 65(1-2): 55-63.

12. West DC, Thompson WD, Sells PG, Burbridge MF, Angiogenesis Assays Using Chick Chorioallantoic Membrane. Methods Mol Med 2001; 46:107-29.

13. National Institute of Health. Public Health Service Policy on Humane Care and Use of Laboratory Animals. USA, 2002.

14. Yim TK, Wu WK, Pak WF, Ko KM. Hepatoprotective action of an oleanolic acid-enriched extract of Ligustrum lucidum fruits is mediated through an enhancement on hepatic glutathione regeneration capacity in mice. Phytother Res 2001; 15: 589-592.

15. Ismaili $H$, Tortora S, Sosa S, Fkih-Tetouani S, Ilidrissi A, Della Loggia R, Tubaro A, Aquino R. Topical antiinflammatory activity of Thymus willdenowii. $J$ Pharm Pharmacol 2001; 53(12): 1645-52.

16. Cardenas $C$, Quesada AR, Medina MA. Effects of ursolic acid on different steps of the angiogenic process. Biochem Biophys Res Commun 2004; 320(2): 402-8.

17. Aggarwal BB, Takada $Y$, Oommen OV. From chemoprevention to chemotherapy: common targets and common goals. Expert Opin Investig Drugs 2004; 13(10): 1327-38.

18. Harmand PO, Duvel R, Delage C, Simon A. Ursolic acid induces apoptosis through mitochondrial intrinsic pathway and caspase-3 activation in M4Beu melanoma cells. Inter J Cancer 2005; 114: 1-11. 
19. Tan ML, Sulaiman SF, Najimuddin N, Samian MR, Muhammad TS. Methanolic extract of Pereskia bleo (Kunth) DC. (Cactaceae) induces apoptosis in breast carcinoma, T47-D cell line. J Ethnopharmacol 2005; 96(1-2): 287-94.
20. Ribatti $D$, Vacca A, Roncali L, Dammacco F. The chick embryo chorioallantoic membrane as a model for in vivo research on angiogenesis. Inter J Dev Biol 1996; 40: 1189-97. 